\title{
Changes in Users Trends Before and During the COVID-19 Pandemic on WHO's Online Learning Platform
}

\author{
Heini UTUNEN ${ }^{\mathrm{a}, 1}$, Ngouille NDIAYE ${ }^{\mathrm{a}}$, Lama MATTAR ${ }^{\mathrm{a}}$, Paula CHRISTEN ${ }^{\mathrm{a}}$, \\ Oliver STUCKE ${ }^{\text {a }}$ and Gaya GAMHEWAGE ${ }^{\mathrm{a}}$ \\ ${ }^{a}$ World Health Organization, Geneva, Switzerland
}

\begin{abstract}
OpenWHO provides open access, online, free and real time learning responses to health emergencies. Before the pandemic, courses on 18 diseases were provided. The increase to 38 courses in response to COVID-19 have led to a massive increase in the number of new learners. As a result, the COVID-19 pandemic affected learners' trends. This paper presents initial findings of changes perceived in the use and user groups' attendance to the World Health Organization's (WHO) health emergency learning platform OpenWHO. Enrolment statistics were based on data collected in December 2019 and March 2021. A descriptive analysis was conducted to explore changes in the usage pattern of the platform. Several user characteristics shifted between before and during the pandemic. More women, younger and older learners joined the learning during the pandemic. Public health education leaned toward a more equitable reach including previously underrepresented groups.
\end{abstract}

Keywords. Online Learning, COVID-19, OpenWHO, Public Health Emergencies

\section{Introduction}

OpenWHO provided 18 different disease courses before the COVID-19 pandemic, and 38 courses for COVID-19 response have led to a massive increase in the number of new learners from 140,000 users in 2019, to 5,100,000 by 31 March 2021. A significant change in use by women users, geographical location, and user characteristics. The pandemic, along with the consequent imposed social distancing boosted online learning [1]. This paper presents initial findings of changes perceived in the use and user groups' attendance to OpenWHO.

\section{Methods}

The enrolment data statistics were drawn from OpenWHO's built-in reporting system, which tracks learners' enrolments, completion rates, demographics and other key courserelated data and later processed and disaggregated using Microsoft ${ }^{\circledR}$ Power BI tool to analyze changes in the usage pattern of the platform comparing users' trends.

\footnotetext{
${ }^{1}$ Corresponding Author, Heini Utunen; E-mail: utunenh@who.int.
} 


\section{Result}

The proportion of women attending the online learning on OpenWHO grew to $51 \%$ (from $40 \%$ ). Still, female learners show lower enrolments (43\%) to the health topics other than COVID-19. Users identifying themselves as Other changed from $>0.1 \%$ to $0.15 \%$. Overall completion rates have increased from $39 \%$ before the pandemic, to $54 \%$ during the pandemic. The online learning platform has spanned to older and younger user groups. The user group of +70 years now account for $5 \%$ of users. Also, the age group of less than 20 years old has grown from 3\% pre-pandemic to 11\%. OpenWHO's most popular courses, essentially infectious diseases, were highest in the WHO African region (24\%). This has decreased to 7\%. Examining the platform use based on countries' classification by income level based on the World Bank classification, a remarkable change before and during the pandemic can be witnessed.

Table 1. The platform uses in low-, middle- and high-income countries in 2019 and 2021.

\begin{tabular}{|c|c|c|c|}
\hline $\begin{array}{c}\text { Country classification / } \\
\text { \% Of enrolments }\end{array}$ & $\begin{array}{c}\text { Low-income } \\
\text { countries }\end{array}$ & $\begin{array}{c}\text { Middle-income } \\
\text { countries }\end{array}$ & $\begin{array}{c}\text { High-income } \\
\text { countries }\end{array}$ \\
\hline $\mathbf{2 0 1 9}$ & $14.20 \%$ & $40.19 \%$ & $45.62 \%$ \\
\hline $\mathbf{2 0 2 1}$ & $3.38 \%$ & $70.72 \%$ & $25.89 \%$ \\
\hline
\end{tabular}

\section{Discussion}

More women, younger and older learners used the WHO's learning platform during the pandemic. Public health education leaned toward a more equitable reach including previously underrepresented groups. WHO's platform helped in bypassing the gender inequity in access to education during the pandemic. Our results align with online learning paralleling the rise of the burden of COVID-19. Higher COVID-19 prevalence in high-income countries is coherent with more users in these locations.

\section{Conclusions}

The pandemic has led to increased learner commitment and new learners from the general public and those vulnerable to the disease, thus expanding and equalizing public health education to previously underrepresented groups. Open online learning ensures the wide access to emergency knowledge for both professionals in public health and to the general public.

\section{References}

[1] Dhawan S. Online learning: A panacea in the time of COVID-19 crisis. Journal of Educational Technology Systems. 2020 Sep;49(1):5-22. 